\title{
Abrasive Waterjet CUTting
}

\author{
Tomáš Kroupa, Milan Daňa \& Miroslav Zetek
}
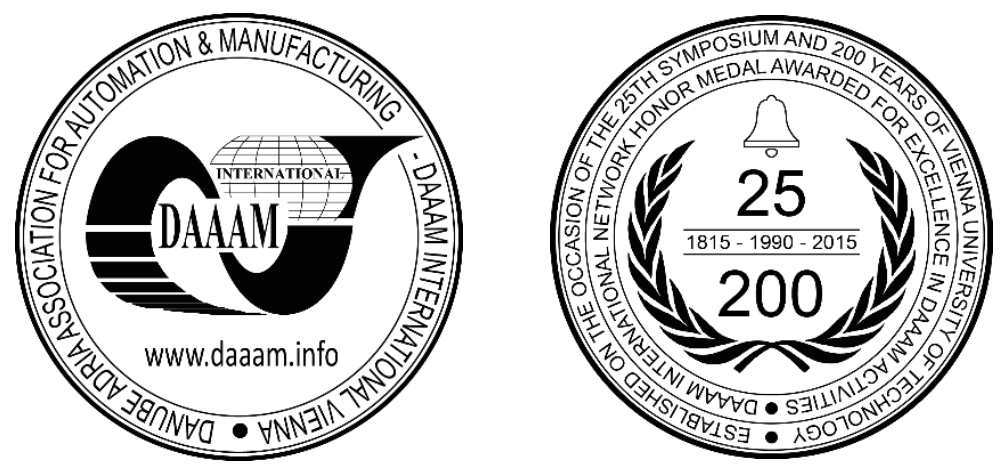

This Publication has to be referred as: Kroupa, T[omas]; Dana, M[ilan] \& Zetek, M[iroslav] (2017). Abrasive Waterjet Cutting, Proceedings of the 28th DAAAM International Symposium, pp.0493-0499, B. Katalinic (Ed.), Published by DAAAM International, ISBN 978-3-902734-11-2, ISSN 1726-9679, Vienna, Austria DOI: $10.2507 / 28$ th.daaam.proceedings.069

\begin{abstract}
Waterjet cutting is being used more and more frequently, for several reasons. One of its major advantages is the possibility to cut almost all materials and thicknesses. This technology can be used for very hard, tough materials (steel, aluminum, dural, mineral materials, plastic) and also soft materials such as rubber. The principle of waterjet cutting is the removal of material by the mechanical impact of a narrow waterjet at high speed. The waterjet is generated by the high pressure of the water as it passes through the nozzle. The cut width is about $0.3 \mathrm{~mm}$, which ensures little loss of material. Deflection (curving) and deceleration of flow occurs during cutting, which is a consequence of the friction between the surface of the waterjet and the surface of the workpiece material. The trajectory of the waterjet is rounded and its radius changes according to the previous arc length. These properties affect the final shape of the surface and topography of the machined parts. Another significant advantage of this cutting method is that the workpiece is not affected by heat and relatively high accuracy is achieved. The use of modern devices often eliminates the need for further machining.
\end{abstract}

Keywords: Abrasive waterjet; cutting quality; cutting angle; eliminating bevels; high pressure pump

\section{Introduction}

The experiment is based on the comparison of results from cutting machines using AWJ technology and machines using DWJ technology. Machines with DWJ technology should achieve an overall higher quality of cutting and should eliminate chamfers on the machined material.

Below is shown the comparison of the cutting methods. For each sample is shown a graph of the dependence of the average feed rate speed of the cutting head on the width of the samples. For comparison, the values for cutting methods AWJ and DWJ are always shown in one graph for a given material and thickness. A digital caliper was used for detecting the width of the samples at two positions (estimating the size of the chamfer on the samples). The values in the tables are the averages of four measurements. The upper position was measured about $1 \mathrm{~mm}$ to $2 \mathrm{~mm}$ from the upper edge, the lower position was measured $1 \mathrm{~mm}$ to $2 \mathrm{~mm}$ from the bottom edge.

Another graph shows the dependence of feed rate speed on the average arithmetic deviation of the profile Ra cut area, which was measured on the length of the sample (in the central part) and in two positions - upper (1-2 mm from the top) and lower (1-2 mm from the lower edge). The values for comparing (AWJ, DWJ) are placed in one graph. 


\begin{tabular}{|c|c|c|}
\hline Type of waterjet cutting & AWJ & DWJ \\
\hline Pressure [bar] & 3800 & 5500 \\
\hline Abrasives & Indian garnet & Indian garnet \\
\hline Grain abrasives & MESH 80 & MESH 80 \\
\hline Abrasive flow [g.min-1] & 540 & 540 \\
\hline Waterjet nozzle diameter (ruby) [mm] & 0.3302 & 0.3556 \\
\hline Abrasive nozzle diameter [mm] & 1.02 & 1.02 \\
\hline
\end{tabular}

Table 1. Waterjet parameters

\section{Figures Technological possibilities of the 3D abrasive waterjet}

\subsection{Technology of Dynamic Waterjet (DWJ)}

Bending of the waterjet and chamfers can be eliminated by reducing the cutting speed. However, this means longer cycle times, thereby increasing production costs.

Dynamic Waterjet technology corrects the bending waterjet and chamfer of the cutting edge at maximum cutting speeds with high accuracy. A sample created without using DWJ is shown in Fig. 1a. The same sample made on a machine using DWJ is shown in Fig 1b. At first sight there is a noticeable difference, primarily in the incidence of the chamfers and the quality of the cut surface.
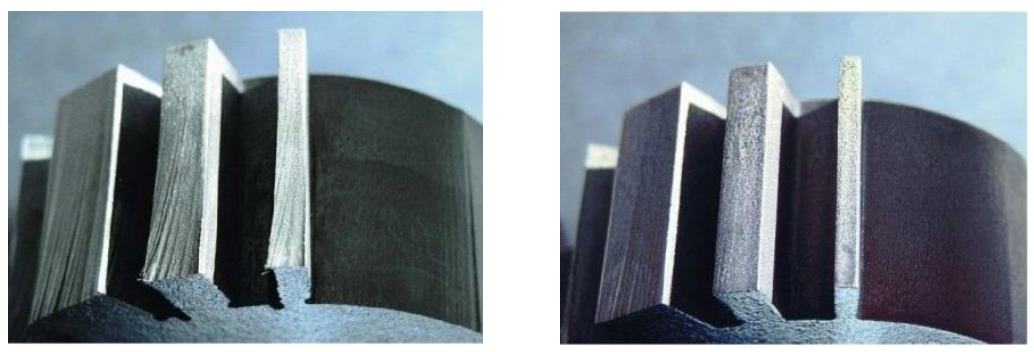

Fig. 1. Waterjet cutting (a) without DWJ (b) with DWJ

\subsection{Abrasive Waterjet (AWJ)}

When using AWJ, water contributes to the introduction of abrasives at higher speeds when it enters the mixing chamber (the abrasive obtains a high kinetic energy and momentum) and for removal of the abrasives and microparticles of the workpiece. It also acts as an opening wedge for increasing the rate of crack spreading in the erosion process. [7]

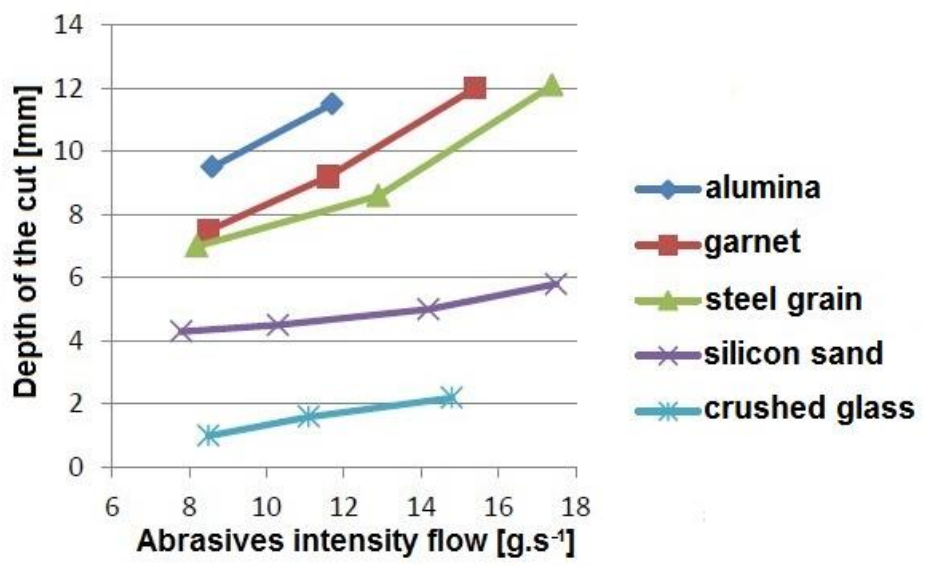

Fig. 2. Dependence of the depth of the cut on the intensity of the abrasive flow

\begin{tabular}{|c|c|c|}
\hline Pressure [MPa] & speed [mm.s-1] & Type of steel \\
\hline 207 & 4,1 & DIN 35CrNiMo6 \\
\hline
\end{tabular}

Table 2. Cutting conditions 
Abrasive factors which have an impact on the depth of the cut are the kind of abrasive used, its sharpness, hardness and grain. The most suitable shapes are abrasive particles with high roundness and low circularity. Fig. 2 shows the dependence of the depth of the cut on the intensity of the flow of various kinds of abrasives when cutting low alloy structural steel.

The graph shows that with an increase in the mass flow of the abrasive to the waterjet, the depth of the cut increases. However, this can only be applied until the critical mass flow. When it is exceeded, the depth of the cut does not increase, but starts to decline. This is because part of the energy is consumed during collisions between the abrasive particles.

Other factors affecting AWJ include the parameters of the abrasive mix. The shape and dimensions of the mixing chamber and the abrasive of the nozzle play an important role. The dimensions of the mixing chamber and the fluid pressure relate to the maximum mass flow of abrasive. In this chamber the character of the flow layers of fluid changes from laminar to turbulent, a vacuum is formed which results in the suction of the abrasive from the tray. Here direct proportion applies - the higher the vacuum, the greater is the maximum mass flow of the abrasive. The initial mixing of the abrasive with the liquid stream continues in the mixing chamber. [3, 7]

\section{The experiment}

In the following part, two tables are shown first (one for AWJ technology and the second for DWJ technology), which relate to one of the cut materials with a certain thickness. Then there are two graphs, which are based on the preceding tables.

The tables include information from a particular cut sample. The type of cut material, its thickness, the technology used for the cut, feed rate of cutting head and time of cutting. The measured values are also shown. First is given the sample width measured at the top and bottom positions. The Ra values of the cutting area (measured along the length of the sample) are shown, which were again measured at two positions, top and bottom. The values of Rz in two positions are also noted.

Below the two tables there are two graphs. The first shows the dependence of the width of the sample on the speed of the cutting head. The second graph shows the relation of the arithmetic deviations of profile Ra to the speed of the cutting head. [2]

\subsection{Abrasive Waterjet (AWJ) Cutting of aluminium}

\begin{tabular}{|c|c|c|c|c|c|c|}
\hline \multirow{2}{*}{\multicolumn{2}{|c|}{$\begin{array}{c}\text { Aluminium 5083AW 15mm } \\
\text { Technology: AWJ }\end{array}$}} & \multicolumn{5}{|c|}{ Average feed rate speed [mm.min-1] } \\
\hline & & 150 & 200 & 250 & 300 & 350 \\
\hline \multicolumn{2}{|c|}{ Cutting time [s] } & 480 & 36 & 29 & 24 & 21 \\
\hline \multirow{2}{*}{$\begin{array}{l}\text { Measurement } \\
\text { sample } \\
\text { position width }\end{array}$} & Upper $[\mathrm{mm}]$ & 19.81 & 19.82 & 19.82 & 19.85 & 19.86 \\
\hline & Lower $[\mathrm{mm}]$ & 20 & 20.05 & 20.13 & 20.21 & 20.23 \\
\hline \multirow{2}{*}{$\begin{array}{l}\text { Measuring } \\
\text { position Ra }\end{array}$} & Upper [mm] & 4.41 & 4.76 & 4.28 & 4.99 & 4.51 \\
\hline & Lower $[\mathrm{mm}]$ & 5.10 & 6.34 & 5.31 & 5.28 & 6.34 \\
\hline \multirow{2}{*}{$\begin{array}{l}\text { Measuring } \\
\text { position Rz }\end{array}$} & Upper [mm] & 27.09 & 28.60 & 25.42 & 30.70 & 29.71 \\
\hline & Lower $[\mathrm{mm}]$ & 30.67 & 36.41 & 31.18 & 30.83 & 35.58 \\
\hline
\end{tabular}

Table 3. Values of the sample from aluminium with thickness $15 \mathrm{~mm}$, cutting technology AWJ

\begin{tabular}{|c|c|c|c|c|c|c|}
\hline \multirow{3}{*}{\multicolumn{2}{|c|}{$\begin{array}{c}\text { Aluminium 5083AW 15mm } \\
\text { Technology: DWJ }\end{array}$}} & \multicolumn{5}{|c|}{ Average feed rate speed [mm.min-1] } \\
\hline & & 277 & 343 & 400 & 450 & 522 \\
\hline & & $60 \%$ & $80 \%$ & $100 \%$ & $120 \%$ & $140 \%$ \\
\hline \multicolumn{2}{|c|}{ Cutting time $[\mathrm{s}]$} & 26 & 21 & 18 & 16 & 14 \\
\hline \multirow{2}{*}{$\begin{array}{c}\text { Measurement } \\
\text { sample } \\
\text { position } \\
\end{array}$} & Upper $[\mathrm{mm}]$ & 19.94 & 19.98 & 19.92 & 19.90 & 20.03 \\
\hline & Lower [mm] & 20 & 20.02 & 20.02 & 20.02 & 20.11 \\
\hline \multirow{2}{*}{$\begin{array}{l}\text { Measuring } \\
\text { position Ra }\end{array}$} & Upper [mm] & 4.31 & 4.06 & 4.56 & 4.29 & 4.35 \\
\hline & Lower $[\mathrm{mm}]$ & 6.22 & 6.29 & 7.84 & 7.03 & 10.03 \\
\hline \multirow{2}{*}{$\begin{array}{l}\text { Measuring } \\
\text { position Rz }\end{array}$} & Upper [mm] & 24.74 & 24.83 & 29.46 & 26.07 & 26.05 \\
\hline & Lower $[\mathrm{mm}]$ & 33.48 & 37.21 & 41.83 & 38.06 & 46.87 \\
\hline
\end{tabular}

Table 4. Values of the sample from aluminium with thickness $15 \mathrm{~mm}$, cutting technology DWJ 


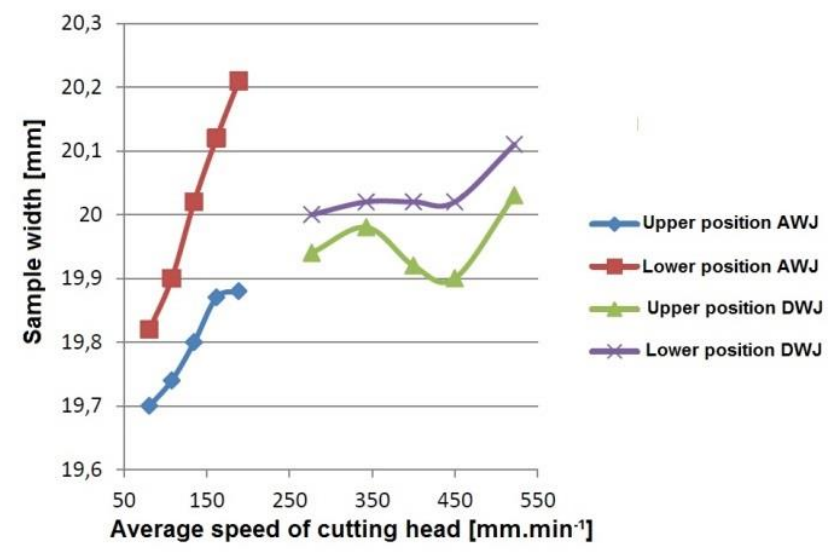

Fig. 3. Dependence of the sample width on the speed of cutting head (aluminium, width $15 \mathrm{~mm}$ )

Fig. 3 confirms that when cutting aluminum with thickness $15 \mathrm{~mm}$ using DWJ technology, the values of the chamfer are at a minimum. Increasing the average feed rate speed when cutting this thickness has a minimal effect on the size of the chamfer. However, this is different when cutting with AWJ technology, where the size of the chamfer increases with the increased average speed of the cutting head. [1]

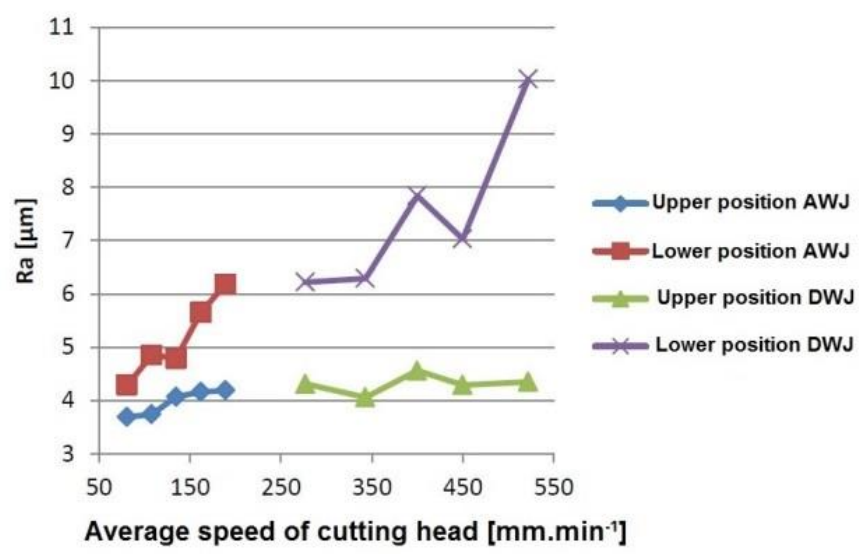

Fig. 4. Dependence of the Ra cut surface on the speed of cutting head (aluminium, width $15 \mathrm{~mm}$ )

Fig. 4 shows that when cutting aluminum with a thickness of $15 \mathrm{~mm}$, higher values of Ra are obtained using DWJ cutting technology. There is also a significant difference between the values of the upper and lower positions because of the higher feed rate of the cutting head. The value of $\mathrm{Ra}$ is almost constant in the lower position with DWJ cutting technology. [4]

\subsection{Cutting of steel}

\begin{tabular}{|c|c|c|c|c|c|c|}
\hline \multirow{2}{*}{\multicolumn{2}{|c|}{$\begin{array}{l}\text { Steel } 11523 \text { 15mm } \\
\text { Technology: AWJ }\end{array}$}} & \multicolumn{5}{|c|}{ Average feed rate speed [mm.min-1] } \\
\hline & & 60 & 80 & 100 & 120 & 140 \\
\hline \multicolumn{2}{|c|}{ Cutting time [s] } & 120 & 90 & 72 & 60 & 51 \\
\hline \multirow{2}{*}{$\begin{array}{l}\text { Measurement } \\
\text { sample } \\
\text { position width }\end{array}$} & Upper $[\mathrm{mm}]$ & 19.90 & 19.93 & 19.98 & 19.99 & 20.00 \\
\hline & Lower $[\mathrm{mm}]$ & 20.41 & 20.44 & 20.61 & 20.68 & 20.82 \\
\hline \multirow{2}{*}{$\begin{array}{l}\text { Measuring } \\
\text { position Ra }\end{array}$} & Upper $[\mathrm{mm}]$ & 3.15 & 2.89 & 2.8 & 3.08 & 3.63 \\
\hline & Lower [mm] & 4.29 & 5.24 & 4.59 & 5.93 & 7.79 \\
\hline \multirow{2}{*}{$\begin{array}{l}\text { Measuring } \\
\text { position Rz }\end{array}$} & Upper [mm] & 20.51 & 18.74 & 17.72 & 20.81 & 22.29 \\
\hline & Lower $[\mathrm{mm}]$ & 22.78 & 27.57 & 24.71 & 30.27 & 37.20 \\
\hline
\end{tabular}

Table 5. Values of the sample from steel with thickness $15 \mathrm{~mm}$, cutting technology AWJ 


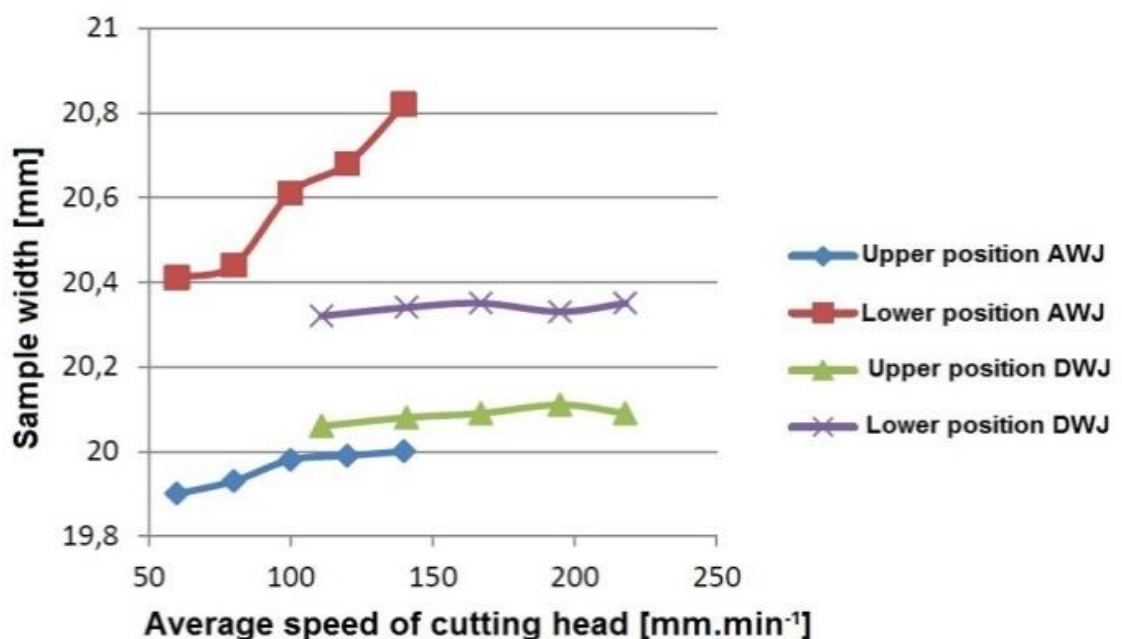

Fig. 5. Dependence of the sample width on the speed of cutting head (aluminium, width $15 \mathrm{~mm}$ )

In Fig. 5 for cutting steel with thickness $15 \mathrm{~mm}$ it is obvious that the chamfer when cutting with DWJ technology is significantly lower than with AWJ technology. Also, the value of the chamfer when using DWJ technology is almost constant when increasing the average speed of the cutting head. There is also a minimal increase in the width dimensions of the sample when increasing the average speed of the cutting head. However, with AWJ cutting technology, the value of the lower measurement position rises dramatically with the increasing speed of the cutting head. Therefore, the width of the sample in the lower position (chamfer) increases. [5]

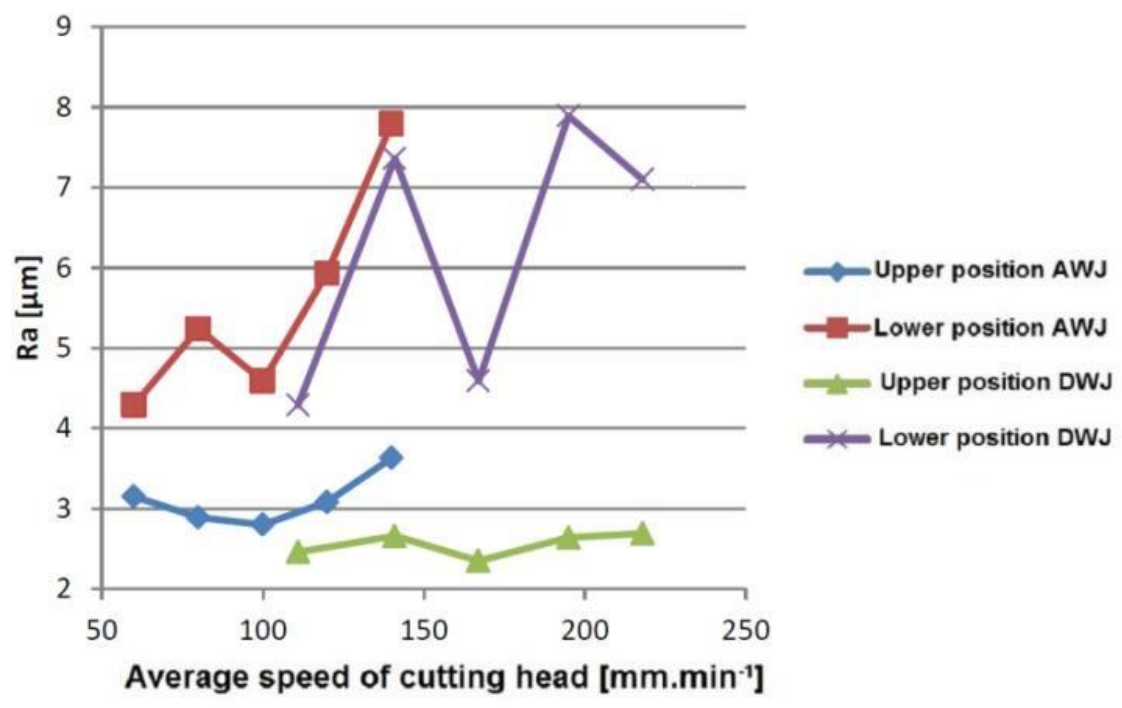

Fig. 6. Dependence of the Ra cut surface on the speed of cutting head (steel, width $15 \mathrm{~mm}$ )

Fig. 6 shows that when cutting steel with thickness $15 \mathrm{~mm}$ using DWJ technology, lower values of Ra (at speeds comparable with AWJ technology) are achieved. The growth of Ra values when using AWJ technology is small, if the notional boundary of the standard speed is not exceeded. Then comes a sharp increase in values in the lower position. Deviations of $\mathrm{Ra}$ (sharp increase of the value) when using DWJ cutting technology were observed. This deviation could be caused for example by placing the measuring tip into a place with distinct striations. Measured values of Ra in the upper positions cut with DWJ technology are very low. In standard operating conditions, the values of Ra measured on samples cut with DWJ technology were lower than with AWJ technology. [1]

The figures below are samples of AWJ and DWJ cutting technologies (steel, $15 \mathrm{~mm}$ thickness). Two samples are placed side by side on one flat surface. One was cut with the lowest average feed rate of the cutting head (on the highest quality of the cut $-60 \%$ ), the second with the highest average feed rate of the cutting head (at the lowest quality - 140 $\%)$. Fig. 7a shows examples of cutting steel using AWJ technology. The large chamfer is noticeable in the figure, which is produced when cutting with AWJ technology.

Fig. 7b shows examples of cutting steel using DWJ technology. In this case the chamfer is minimal, and hardly recognizable by eye. 


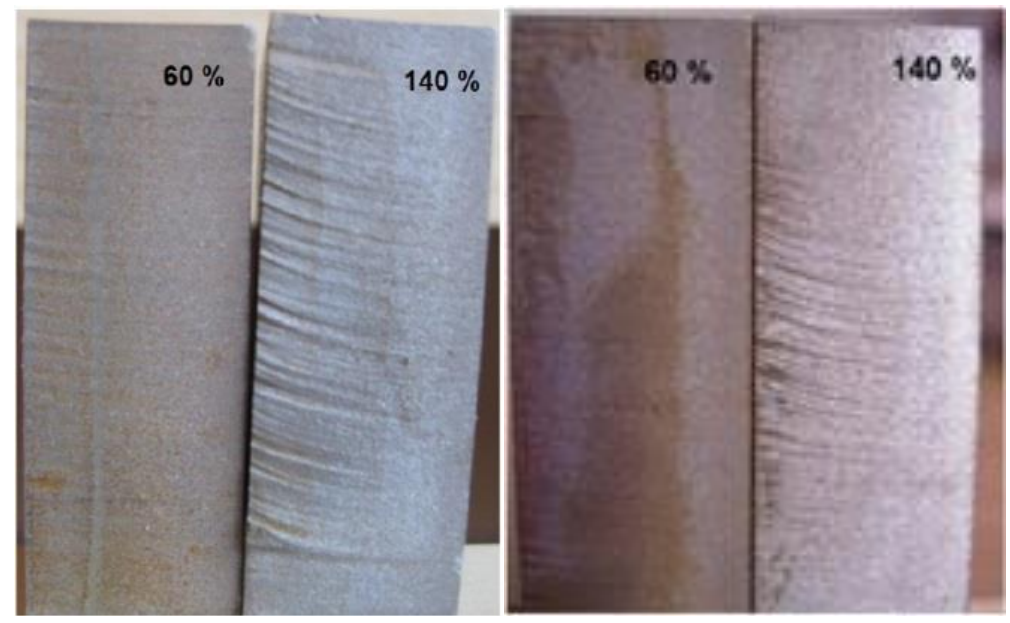

Fig. 7. Waterjet cutting (a) using technology AWJ (b) using technology DWJ

In both figures the deteriorating quality of the surface is obvious as the speed of the cutting head increases. Visual inspection reveals the lower quality of the sample surfaces (in this material) which are cut using DWJ technology.

\section{Evaluation of the experiment}

A total of 60 samples were cut in the experiment. Half the samples were cut by AWJ technology and the second half by DWJ technology. Evaluation shows that cutting using DWJ technology fulfils expectations regarding the chamfer of the samples. A minimal chamfer was measured on all the samples (two kinds of material) in comparison with the measured values from the AWJ technology. In most cases with cutting technology DWJ the chamfer increased minimally with increasing average speed of the cutting head. When comparing the size of the chamfers of each kind of material it was found that there are minor differences in the upper and lower positions on the aluminum samples. This is probably because it is a material with a lower specific density, meaning that the waterjet penetrates it more easily than steel without changing direction. Using AWJ technology there was a visible change in roughness when cutting corners. This was caused by the deceleration of the waterjet when it entered the corners. [2],[3]

\section{Conclusion}

For the second comparison, comparing the average arithmetic deviations of the profile Ra, the assumption has not been confirmed. Only when cutting steel with thickness $15 \mathrm{~mm}$ using DWJ technology were lower Ra values achieved than when cutting with AWJ technology. The comparison was made in terms of feed rate speed, which is used on each machine to achieve the quality of cut corresponding to the standard.

When measuring the arithmetical deviations of the profiles on the samples from aluminum and steel it was found that the expected results were not achieved. The samples from aluminum and steel cut by AWJ technology have significantly better Ra values than the samples using DWJ technology. Also, the differences between the upper and lower Ra values were significantly higher when cutting with DWJ technology. The results using the various methods from cutting at varying average speeds of the cutting head were compared. The cutting heads had enough velocity to achieve the optimal quality of the cut on the machine. [8]

At first sight, visual comparison of the samples reveals smaller chamfers on both materials when using DWJ technology. This method does not generate a change of roughness on the corners, which arises when using AWJ technology due to the slowing of the cutting head.

Regarding the quality of the surface and depth of the striations in the aluminum samples, the samples cut using DWJ technology seem visually worse. This finding refutes the assumption that there would be higher quality cutting for all the sample materials. The differences in values of the quality for aluminum are probably due to its low specific density. The waterjet with abrasive passes through the material easier (due to a pressure of 5500 bar and high average cutting speed) and leaves significant grooves and striations. On steel samples with a thickness of $15 \mathrm{~mm}$, the samples cut with DWJ technology appear visually better, which confirms the assumption. [9]

For better results would be necessary to measure samples on the multiple levels. Sample measure also at the beginning, where the speed of the head increases, in the middle where the feed rate is highest and at the end, where cutting head slows down.

\section{Acknowledgements}

This paper is based upon work sponsored by project SGS-2016-005 


\section{References}

[1] Loeser, C. Duerr, H. \& Pilz, R. Application of the Micro Water Abrasive Injector Fine Jet for Precision Machining, Annals of DAAAM for 2010 \& Proceedings of the 21st International DAAAM Symposium, Volume 21, No. 1, ISSN 1726-9679 ISBN 978-3-901509-73-5, Editor B. Katalinic, Published by DAAAM International, Vienna, Austria, EU, 2010

[2] Begic-Hajdarevic. D. Cekic. A. Mehmedovic. M. Djelmic. Experimental Study on Surface Roughness in Abrasive Water Jet Cutting 25th DAAAM International Symposium on Intelligent Manufacturing and Automation, DAAAM 2014 Experimental Study on Surface Roughness in Abrasive Water Jet Cutting, Procedia Engineering 100 ( 2015 ) $394-399$

[3] D. Krajcarz, Comparison metal water jet cutting with laser and plasma cutting, in: Proceeding of 24th DAAAM International Symposium on Intelligent Manufacturing and Automation, Procedia Engineering 69 (2014) 838-843.

[4] F. Boud, L. F. Loo, P. K. Kinnell, The Impact of Plain Waterjet Machining on the Surface Integrity of Aluminium 74752nd CIRP Conference on Surface Integrity (CSI), Procedia CIRP 13 ( 2014 ) $382-386$

[5] G. Holmqvist, U. Honsberg, Sensitivity analysis of abrasive waterjet cutting economy, in: Proceeding of 19th International Conference on Water Jetting, Nottingham University, UK, 2008, pp. 273-287 [6] http://www.insse.ro, (Year). The National Statistics Institute, Statistics Year Book, Accessed on: 2009-08-13

[7] M.Gent, M.Menédez, S.Torno, J.Toraño, Experimental evaluation of the physical properties required of abrasives for optimizing waterjet cutting of ductile materials, Wear, Volumes 284-285, 25 April 2012, Pages 43-51

[8] A. Akkurt, M.K. Kulekci, U. Seker, F. Ercan, Effect of feed rate on surface roughness in abrasive waterjet cutting applications, Journal of Materials Processing Technology 147 (2004) 389-396.

[9] Borkowski J., Sutowska M. (2007). The quality of surface cut after high-pressure abrasive-water cutting, Journal of Machine Engineering,Vol.7(3), pp.19-28 